\title{
Evaluation of type of kinematics on glide path procedures and torsional fatigue resistance after preparation of moderately curved canals
}

\section{Murilo Priori ALCALDE(a) (1)}

Marco Antonio Hungaro DUARTE(a) Pedro Henrique Souza CALEFI(a)

Victor de Moraes CRUZ ${ }^{(a)}$

Bruno Carvalho de VASCONCELOS ${ }^{(b)}$

Marcus Vinícius Reis SÓ(c)

Rodrigo Ricci VIVAN(a) (C)

(a) Universidade de São Paulo - USP, Bauru School of Dentistry, Department of Dentistry, Endodontics and Dental Materials, Bauru, SP, Brazil.

(b) Universidade Federal do Ceará - UFCE, Department of Dentistry, Sobral, CE, Brazil.

(c) Universidade Federal do Rio Grande do Sul - UFRGS, Department of Dentistry, Porto Alegre, RS, Brazil.

Declaration of Interests: The authors certify that they have no commercial or associative interest that represents a conflict of interest in connection with the manuscript.

Corresponding Author:

Murilo Priori Alcalde

E-mail:murilo_alcalde@hotmail.com

https://doi.org/10.1590/1807-3107bor-2021.vol35.0064

Submitted: August 8, 2020

Accepted for publication: December 3, 2020

Last revision: Januray 20, 2021
Abstract: Sixty moderately curved canals of mandibular molars classified as Vertucci's type IV canal configuration were selected by micro-CT 1174. The teeth were divided into two groups according to the kinematics used, whether reciprocating or rotary motion $(n=30$, totaling 60 mesial root canals). The instruments used to perform the glide path procedures had identical features $(0.15 \mathrm{~mm}$ of tip size, $0.04 \mathrm{~mm} / \mathrm{mm}$ taper, thermal treatment, and square cross-section), but differed in the direction of the cutting blade. The duration of the procedure and the absolute and percentage frequency of the instruments to reach the full working length were recorded. The torsional test (3630-1; 1992) was performed on both used and unused instruments, to evaluate a possible reduction in the torsional resistance when using the glide path procedure. Statistical analysis was performed using the unpaired $t$-test and the chi-square test, and the level of significance was set at $5 \%$. The type of kinematics used affected the duration of glide path procedures, and the reciprocating motion seemed to induce less torsional stress during glide path procedures.

Keywords: Endodontics; Dental Instruments; Root Canal Preparation.

\section{Introduction}

The glide path procedure has been widely used during root canal preparation, because of its several benefits, such as less canal transportation, ${ }^{1,2}$ smaller risk of instrument fracture, ${ }^{3,4}$ and reduced postoperative pain..$^{5,6}$ Therefore, it has been highly recommended for the root canal preparation of curved and constricted canals. ${ }^{2,7}$

Conventionally, the glide path was performed with conventional stainless steel \#10 hand files. ${ }^{8,9}$ However, engine-driven NiTi instruments with a small tip size and small tapers have been used and are recommended, ${ }^{2,7}$ Several NiTi pathfinding instruments have been introduced, with different cross-section designs, tapers, tip sizes, thermal treatments, and kinematics to improve safety and effectiveness during glide path preparation. ${ }^{10,11}$

The operational aspects of rotary and reciprocating motion have been widely studied to aid in root canal shaping and to determine the cyclic and torsional fatigue resistance of NiTi instruments. ${ }^{12}$ 
Reciprocating motion promotes greater cyclic fatigue resistance and reduces torsional stress. ${ }^{12,13,14}$ Reciprocating motion is also safer than rotary motion in constricted canals, because it reduces the risk of taper lock, and hence that of instrument fracture ${ }^{13,15}$ Engine-driven pathfinding instruments are mainly susceptible to torsional fatigue and the taper lock effect. ${ }^{7,16}$ There is a lack of information regarding how the type of kinematics influences the glide path preparation, and what risk of fracture is posed by pathfinding instruments.

Currently, there are several NiTi rotary and reciprocating glide path files manufactured with different design features (tip diameter, cross-section, a diameter of core, spiral flutes) and types of $\mathrm{NiTi},{ }^{7,17}$ which can affect their clinical performance. ${ }^{7}$ Recently, two new Brazilian pathfinding instruments were introduced on the market: the X1 Glide Path 15.04 (MKLife, Porto Alegre, Brazil) and the Sequence Rotary File 15.04 (MKLife, Porto Alegre, Brazil), recommended for use in reciprocating and rotary motion, respectively. Both instruments have a \#15 tip size and 0.04 fixed taper, and a square cross-section design, and are manufactured with a heat treatment technique similar to that of Blue technology. No data have been reported in the literature on the effectiveness of glide path preparations, or the torsional properties of these instruments.

The technique employed by rotary and reciprocating pathfinding instruments has been previously evaluated for making glide path preparations. ${ }^{6,717}$ However, there is no study assessing the influence of the type of kinematics on the success and safety of the glide path preparation, using instruments with identical features. Therefore, this study aimed to evaluate the influence of reciprocating and rotary motion on the glide path procedure, and also the torsional resistance of the pathfinding instruments after simulated clinical use in moderately curved canals of mandibular molars. The null hypotheses tested were as follows:

a. The different kinematics used in the glide path procedures would not affect the procedure duration, the success rate, the type of instrument deformation or the fracture rate of rotary and reciprocating instruments. b. The different kinematics used in the glide path procedures would not affect the torsional properties of pathfinding instruments.

\section{Methodology}

\section{Sample size calculation}

The sample calculation was performed based on a pilot study, using the G*Power v3.1 for Mac (Heinrich Heine, University of Düsseldorf), and the Wilcoxon-Mann-Whitney test of the $t$-test family. An alpha-type error of 0.05 , a beta power of 0.95 , and a ratio $\mathrm{N} 2 / \mathrm{N} 1$ of 1 were also stipulated. A total of 30 samples (60 mesial root canals per group) were indicated as the ideal size required for observing significant differences.

\section{Teeth specimen selection and groups}

Before conducting the study, the research protocol was approved by the Institutional Research Ethics Committee (ref. $\left.n^{\circ} 18006919.8 .0000 .5417\right)$. Teeth with open apexes, apical root resorption, previous root canal treatment, or root preparation were excluded from the selection of human mandibular molars. The selected teeth were anatomically paired using Micro-Computed Tomography (Micro-CT) SkyScan model 1174 (SkyScan, Kontich, Belgium) with an isotropic resolution of $16.82 \mu \mathrm{m}$. The images obtained of each specimen were reconstructed with an NRecon software program (v.1.6.3 NRecon; BrukermicroCT, Belgium), which provided images of the internal anatomy of axial sections of the canals in BMP format.

\section{Experimental glide path procedures}

A total of $40 \mathrm{NiTi}$ instrument ( $25 \mathrm{~mm}$ in length) systems ( $n=20$ per system) were used in this study, belonging to either the X1 BF 15.04 or the SRF 15.04 system. The glide path procedure inspected each instrument for defects or deformities, under a stereo microscope (Carl Zeiss, USA) at 16X magnification, before the instruments were tested; none were discarded. In addition, all the instruments were identified before being used, and were photographed after and before the glide path procedure at 16X and 32X magnification, to detect possible plastic 
deformation, such as unwinding or winding, or to ascertain that there was no visible defect, as previously described by Sattapan et al. ${ }^{20}$

A single experienced endodontist was previously trained, and performed all the laboratory procedures to standardize apical pressure and amplitude of the handpiece, for the purpose of reducing possible bias. After coronal access and location of the mesial root canal orifices, each tooth was mounted on a specific apparatus (IM do Brazil, São Paulo, Brazil) that simulated the alveolar socket. This apparatus allowed an apex locator (Root ZX; J Morita USA, Irvine, CA, SA) connection to measure the working length during the glide path procedures. Previously, a \#08 K file (Dentsply-Sirona, Bensheim, Germany) was inserted at the level of the mesial root canal orifice to determine the suitable insertion angle for the glide path instruments. This was done without any previously prepared manual glide path. Then, the pathfinding instruments were mounted on a counter-angle handpiece (Dentsply-Sirona, Bensheim, Germany) powered by an electric endodontic motor (VDW Silver Reciproc, Germany), as reported by De-Deus et al. ${ }^{7}$

The glide path procedure was performed using reciprocating motion with the $\mathrm{X} 1$ Blue File 15.04 (Wave-One ALL Function - $350 \mathrm{rpm}, 170^{\circ}$ counterclockwise and $50^{\circ}$ clockwise direction) for Group 1, and rotary motion with the Sequence Rotary File 15.04 (350 rpm and 1.0 N.cm torque) for Group 2. The glide path preparation technique was performed as previously reported by De-Deus et al. ${ }^{7}$ Pathfinding instruments were used with a gentle in-and-out motion of about 2-mm amplitude to reach the full working length (RFWL), which was established when the apex locator so alerted, thus indicating the foramen position. After three pecking motions, the instruments were cleaned, and the root canals were irrigated with $2 \mathrm{~mL}$ of $2.5 \%$ sodium hypochlorite. This step was repeated until the instruments could RFWL. Then, the instruments were maintained on the full working length, and the apical foramen was examined under a dental operating microscope (DF Vasconcellos SA, Valença, Brazil) under 40X magnification to confirm if the instrument was able to RFWL. An attempt was made three times to RFWL in both groups, until resistance was encountered.

The time required for the instruments to RFWL was recorded with a chronometer (in seconds), excluding the irrigation step. All the experimental groups were carried out by a endodontist previously trained for reciprocating and rotary NiTi instruments. Each instrument was used in 3 mesial root canals, and then discarded. All the instruments were cleaned in saline solution, in an ultrasonic cleaning device (Gnatus, Ribeirão Preto, São Paulo, Brazil) for 3 minutes before use.

\section{Torsional fatigue test}

The torsion test was performed using a torsion machine (Analógica, Belo Horizonte, Brazil) to evaluate the torsional resistance of new and used pathfinding instruments, before and after the glide path procedure, respectively. The instruments used in the procedure were randomly selected for the torsional fatigue test. A total of 30 pathfinding instruments $(n=15)$ were used to establish the maximum torque (N.cm) and angular deflection $\left({ }^{\circ}\right)$ needed to produce a fatigue failure. Only 15 instruments were used to test instrument fracture, and the same number of specimens were used for each group.

The torsion tests used in this study were described in previous studies, ${ }^{16,21,22}$ based on the International Organization for Standardization (ISO) 3630-1 (1992). The torque values were assessed by measuring the force exerted on a small load cell by a lever arm linked to the torsion axis. The rotation angle was measured by a resistive angular transducer connected to a process controller. Three millimeters of the instrument tip were clamped with a brass chuck. The speed was set to $2 \mathrm{rpm}$ counterclockwise for X1 BF 15.04 instruments, and 2 rpm clockwise for SRF 15.04 instruments, respectively. The maximum torsional strength and angular rotation to fracture were measured.

\section{SEM evaluation}

Fractured instruments after the torsional test

All the instruments from each group were cleaned ultrasonically after the torsional test. The instruments 
were examined by scanning electron microscopy (JEOL, JSM-TLLOA, Tokyo, Japan) to assess the topographic features of the fractured surface of the instruments. The photomicrographs were taken at $35 \mathrm{X}$ and 200X magnification. Additional photomicrographs were taken at 1000X magnification at the center of the fractured surface of the instruments to gain a more in-depth analysis of the topographic features. A supplementary analysis was also performed on the fractured instruments during the glide path procedure to determine the cause of instrument failure, according to Sattapan et al. ${ }^{20}$

\section{Statistical analysis}

The torsional fatigue resistance data (torque and angular rotation) were analyzed statistically

Table 1. Mean and standard deviations of time (seconds - s), (absolute and percentage frequency of pathfinding instruments to reach the full working length (RFWL) using different kinematics.

\begin{tabular}{lcc}
\hline Variable & Reciprocating & Rotary \\
\hline Time (s) & $40.50( \pm 4.20)^{a}$ & $20.80( \pm 6.45)^{b}$ \\
RFWL & $54(90 \%)^{a}$ & $48(80 \%)^{a}$
\end{tabular}

Different lower-case letters in rows represent significant differences between X1 15.04 and SRF 15.04 regarding the amount of time for the instruments to RFWL (unpaired t test, $p<0.05$ ) and the absolute and percentage frequency of instruments to RFWL (Fisher's exact test, $\mathrm{p}<0.05)$. using the unpaired $t$-test for intra- and intergroup comparisons. The time for the instruments to RFWL was analyzed statistically using the unpaired $t$-test. The types of defects identified, and the number and percentage of fractured instruments after simulated clinical use, were analyzed statistically using the chi-square test. The level of significance was set at $5 \%$ for all the tests.

\section{Results}

The mean and standard deviations of the procedure time, and the absolute and percentage frequency of pathfinding instruments able to RFWL are presented in Table 1 . The rotary motion required significantly less time to RFWL than reciprocating motion $(\mathrm{p}<0.05)$. There was no significant difference between the rotary and reciprocating types of kinematics $(p>0.05)$.

The types of defects identified and the fractured instruments (number and percentages) after simulated clinical use are shown in Table 2. There was no significant difference between the types of kinematics $(p>0.05)$.

The mean and standard deviations of maximum torsional strength, and the angular rotation values of new and used instruments, are presented in Table 3. The intragroup comparison showed that

Table 2. Types of defects identified, and number and percentage of fractured instruments after simulated clinical use of different kinematics.

\begin{tabular}{llcccccccc}
\hline \multirow{2}{*}{ Kinematics } & & \multicolumn{2}{c}{ Unwinding } & \multicolumn{2}{c}{ Winding } & \multicolumn{2}{c}{ No visible defect } & \multicolumn{2}{c}{ Fracture } \\
\cline { 3 - 10 } & $n$ & $n$ & $\%$ & $n$ & $\%$ & $n$ & $\%$ & $n$ & $\%$ \\
\hline Reciprocating & 20 & $9^{a}$ & $45^{a}$ & $4^{a}$ & $20^{a}$ & $6^{a}$ & $30^{a}$ & $1^{a}$ & 5 \\
Rotary & 20 & $7^{a}$ & $35^{a}$ & $7^{a}$ & $35^{a}$ & $3^{a}$ & $15^{a}$ & $3^{a}$ & 15 \\
\hline
\end{tabular}

Different lower-case letters in columns represent significant differences between X1 15.04 and SRF 15.04; n: total number of deformations and fractures observed; \%: percentage of deformations and fractures observed.

Table 3. Mean and standard deviation of torsional strength $(\mathrm{N} . \mathrm{cm})$ and distortion angle $\left(^{\circ}\right)$ of the instruments subjected to the torsional test after glide path preparation using different kinematics

\begin{tabular}{lcccc}
\hline \multirow{2}{*}{ Instrument } & \multicolumn{2}{c}{ Torque $(\mathrm{N} . \mathrm{cm})$} & \multicolumn{2}{c}{ Distortion angle $\left(^{\circ}\right)$} \\
\cline { 2 - 5 } & $\mathrm{New}$ & Used & New & Used \\
Reciprocating & $0.48( \pm 0.038)^{\mathrm{a}, \mathrm{A}}$ & $0.45( \pm 0.050)^{\mathrm{a}, \mathrm{A}}$ & $381.40( \pm 21.87)^{\mathrm{a}, \mathrm{A}}$ & $352.40( \pm 30.19)^{\mathrm{b}, \mathrm{A}}$ \\
Rotary & $0.48( \pm 0.028)^{\mathrm{a}, \mathrm{A}}$ & $0.40( \pm 0.049)^{\mathrm{b}, \mathrm{B}}$ & $378.40( \pm 23.05)^{\mathrm{a}, \mathrm{A}}$ & $327.40( \pm 14.41)^{\mathrm{b}, \mathrm{B}}$ \\
\hline
\end{tabular}

Different lower-case letters in rows represent significant differences between new and used instruments.

Different upper-case letters in columns represent significant differences between X1 15.04 and SRF 15.04 
the used rotary instruments presented a significant reduction in torsional strength and angular rotation, in comparison with the new instruments $(\mathrm{p}<0.05)$, whereas the reciprocating instruments showed significant reduction only in the angular rotation $(p<0.05)$. The intergroup comparison showed no significant differences in maximum torsional strength, or in angular rotation between new reciprocating and new rotary instruments $(\mathrm{p}>0.05)$. However, the used reciprocating instruments showed significantly higher torsional strength and angular rotation than the used rotary instruments $(p<0.05)$.

The SEM evaluation showed that all the instrument fractures occurring during the glide path preparation did so because of torsional fatigue (Figure 1). The torsional test showed typical features of torsional failure. All of the new and used instruments showed abrasion marks and fibrous dimples near the center of rotation (Figure 2).

\section{Discussion}

The aim of this study was to evaluate the influence of reciprocating and rotary motion on the glide path procedure, and compare the torsional fatigue resistance of the pathfinding instruments after simulated clinical use in moderately curved canals of mandibular molars.

The methodology used for glide path preparation in this study was similar to that reported by De-Deus et al. ${ }^{7}$ The selection of the root canal configuration was made by anatomical pairing, using a micro-CT to select mandibular molars with Vertucci's type IV canal configuration (with independent canals) ${ }_{1}^{18}$ and curvatures ranging from $20^{\circ}-25^{\circ} \cdot{ }^{19}$ The root canal volume was calculated and statistically analyzed to select teeth with similar root canal volumes, and a mesiodistal apical anatomical diameter at $1 \mathrm{~mm}$ short of the apex between the groups, thus reducing possible bias. The glide path procedures were performed using instruments with identical features (tip size, type of NiTi alloy, cross-section design), but different cutting blade directions. Therefore, the present study evaluated only the influence of rotary (clockwise cutting blades) and reciprocating (counterclockwise cutting blades) motion instruments, and eliminated other variables.

During glide path procedures, NiTi engine-driven instruments are mainly susceptible to torsional fatigue. ${ }^{7}$ In the present study, the torsional fatigue test was conducted to evaluate the maximum torsional strength and the angle of rotation to instrument fracture after simulated clinical use of different kinematics, and also to compare the used and unused instruments. The torsional test was performed according to ISO Standard 3630-1 specification, and was reported previously in the literature. . $^{16,21,22}$ In this study, $3 \mathrm{~mm}$ of the tip was fastened, and the rotation was made in a clockwise or counterclockwise direction for rotary or reciprocating instruments, respectively. The $3 \mathrm{~mm}$ specification for the tip was adopted because the instrument is more susceptible to fracture at this point rather than at $5 \mathrm{~mm},{ }^{23}$ and also because ISO standard 3630-1 requires it.

This study showed no significant difference between reciprocating and rotary motion regarding absolute and percentage frequency of pathfinding instruments to RFWL, type of instrument deformation, and instrument fracture rate. However, the rotary motion instrument required significantly less time to RFWL than the reciprocating motion instrument; therefore, our first null hypothesis was partially rejected. Reciprocating motion involves rotation in counterclockwise and clockwise directions with a $120^{\circ}$ difference between the two movements. ${ }^{13,14}$ Thus, reciprocating motion requires three cycles to complete $360^{\circ}$ as a rotary motion; this represents a longer amount of time to cut the root dentin, and could explain the results of the reciprocating group.

Some authors have suggested that reciprocating motion helps instruments advance toward the apex without a glide path, and presents a lower risk of instrument fracture during root canal preparation. ${ }^{25,26}$ The results of this study showed that there was no significant difference between rotary and reciprocating motion regarding the absolute and percentage frequency of pathfinding instruments to RFWL. De-Deus et al. ${ }^{7}$ reported that pathfinding instruments should be used with previous manual glide path preparation, because extremal flexibility 
Evaluation of type of kinematics on glide path procedures and torsional fatigue resistance after preparation of moderately curved canals

could make it easier to RFWL, but could also increase the risk of instrument separation. In this study, no manual glide path was performed before using the pathfinding instruments. This allowed us to evaluate only the kinematic influence on glide path procedures. The reciprocating motion probably did
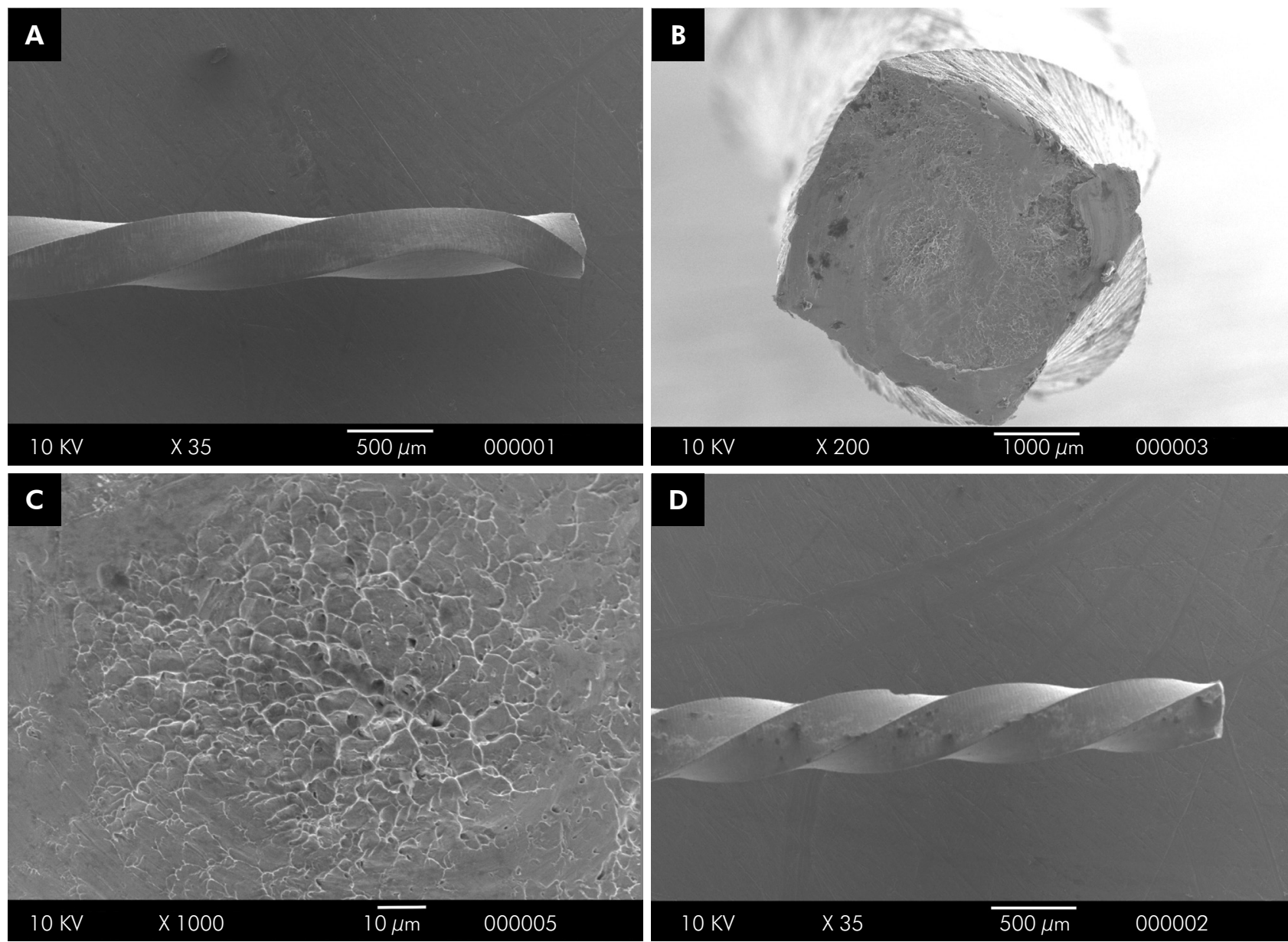

\section{D}
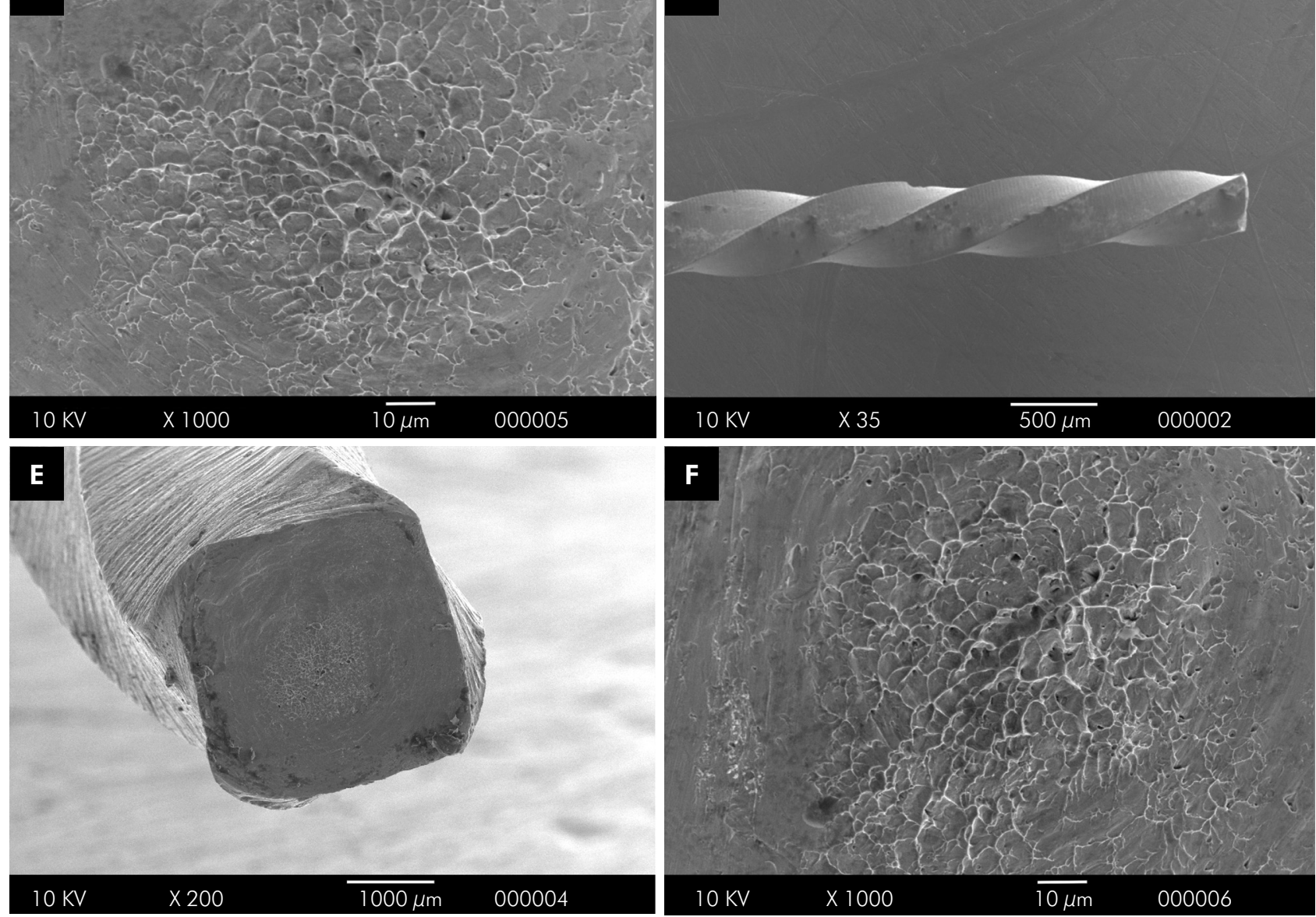

Figure 1. SEM images of fractured reciprocating $(A, B$, and $C)$ and rotary $(D, E$, and $F)$ pathfinding instruments during glide path preparation. Images $A$ and $D$ show a lateral view of the spiral flutes of the instruments at $35 X$ magnification; $B$ and $E$ show the front view of the fragments with the circular box indicating the concentric abrasion mark at 200X magnification; $\mathrm{C}$ and $\mathrm{F}$ show the concentric abrasion mark at 1000X magnification; the skewed dimples near the center of rotation are features typical of torsional failure. 

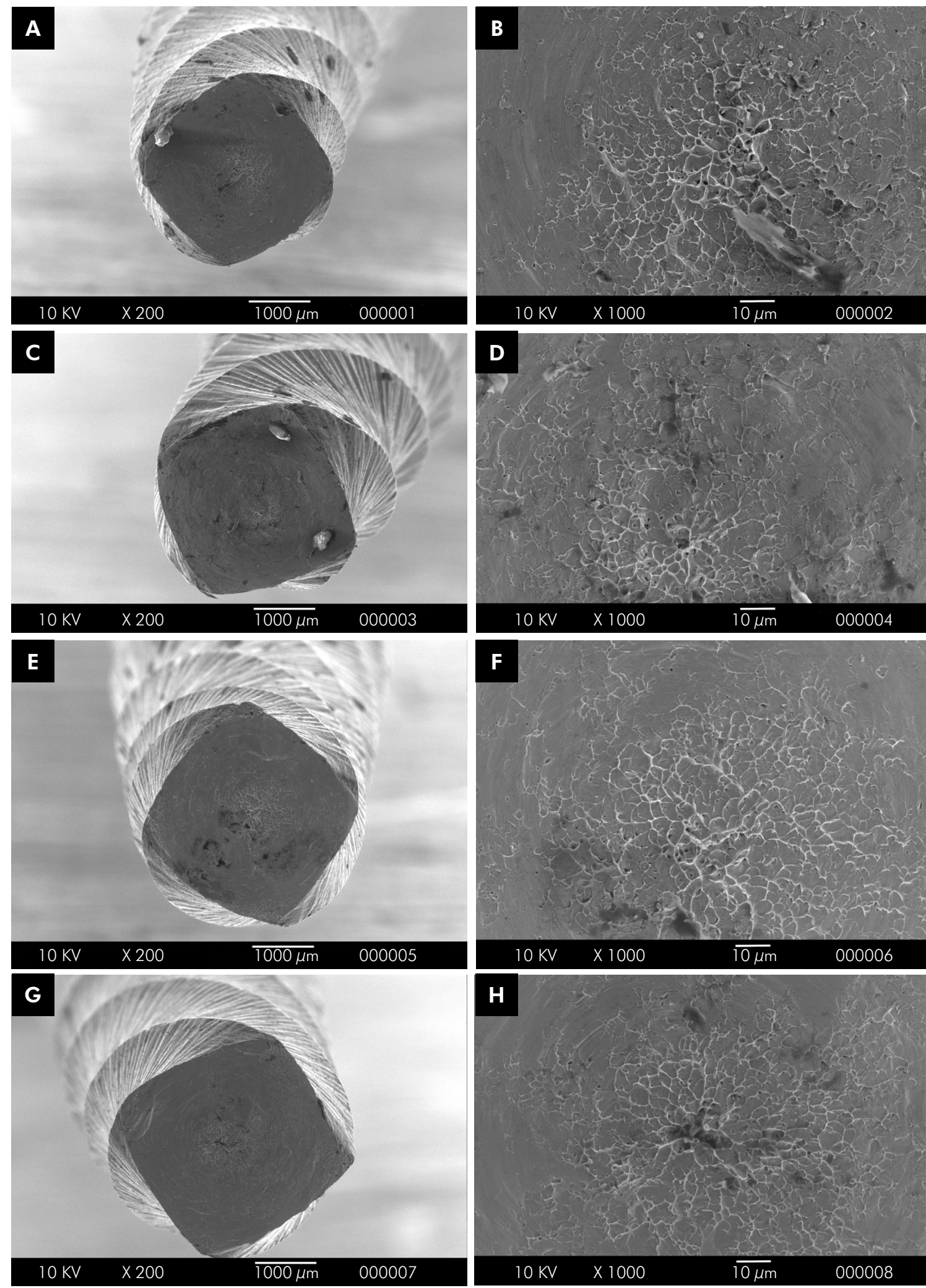

Figure 2. SEM images of separated fragments of unused $A, B$ and used $C, D$ reciprocating, and of unused $E, F$ and used $G, H$ rotary instruments after torsional fatigue testing. The first column shows the front view of the fragments with the circular box indicating the concentric abrasion mark at 200X magnification; the second column shows the concentric abrasion mark at 1000X magnification; the skewed dimples near the center of rotation are features typical of torsional failure for all instruments. 
not perform better than rotary motion because of the causes reported by De-Deus et al., ${ }^{7}$ namely, the reciprocating instrument could not advance toward the apex during canal preparation without a glide path.

The plastic deformation of spiral flutes of the NiTi engine-driven instruments is usually caused by canal roots constricted from torsional stress during root canal preparation. ${ }^{20}$ This property could be considered a safety feature that allows clinicians to visualize metal fatigue and thus avert overuse. ${ }^{27}$ The results of this study showed no significant difference regarding the type of instrument deformation or the rate of fractured instruments. The pathfinding instruments were used in 3 mesial root canals, whose root canal volume, apical diameter, and root curvature were previously paired, thus suggesting that both groups were submitted to similar conditions. The use of pathfinding instruments in 3 root canals probably caused similar mechanical stress for both groups; this corroborates the results of this study with others in the literature. Although there was no significant difference regarding the presence of plastic deformation, or the number of instruments fractured, it could be speculated that reciprocating motion was safer than rotary motion, because it caused a lower rate of instrument fracture, and resulted in the plastic deformation of fewer instruments. These results could be attributed to the alternate rotation in counterclockwise and clockwise directions, which reduces the taper lock and screw-in effect. ${ }^{13,24}$

The torsional test evaluated the maximum torsional strength and angular rotation values of new and used instruments in different kinematics. The results showed that rotary motion promoted a significant reduction in the torsional strength and angular rotation of the used instruments, compared with unused instruments $(p<0.05)$. In contrast, reciprocating motion presented a significant reduction only in angular rotation $(p<0.05)$. Moreover, used reciprocating instruments showed significantly higher torsional strength and angular rotation than used rotary instruments $(p<0.05)$. There was no significant difference between unused rotary and unused reciprocating instruments ( $p>0.05)$. Therefore, our second null hypothesis was rejected.

Previous studies have suggested that reciprocating motion promotes less torsional stress due to the alternating motion direction. ${ }^{13,28,29}$ The results of this study corroborate those mentioned above, by showing that reciprocating motion caused less torsional stress than rotary motion after clinical use. Moreover, clinical use significantly reduced the torsional properties of rotary instruments, as previously reported. ${ }^{30}$ The comparison of used and unused reciprocating instruments showed that there was a significant reduction only in the angular rotation to instrument fracture. These results could be attributed to the plastic deformation of the spiral flutes during the glide path procedure, which probably affected the deformation ability of the instrument without modifying its torsional strength.

TheSEM evaluation showed that all the instrument fractures occurring during the glide path preparation did so because of torsional fatigue (Figure 1). The results of the torsional test showed typical features of torsional failure. All of the new and used instruments showed abrasion marks and fibrous dimples near the center of rotation (Figure 2).

The benefits of reciprocating motion have been poorly explored for glide path preparation until now. There are no reports of the impact of the type of kinematics on the torsional properties of pathfinding instruments, or of the success rates of glide path procedures. The main limitation of this study was that it used two identical instruments (cross-section, tip size, taper, and thermal treatments). Accordingly, we could evaluate only the real effect of the different kinematics on the glide path procedures. Therefore, the authors suggest that future studies should be conducted using different glide path instruments to evaluate the impact of other variables (thermal treatments and design of the instruments) on the results found by this study.

\section{Conclusion}

In conclusion, within the limitation of this study, the type of kinematics did not affect the success rate of the glide path procedures. 


\section{References}

1. Elnaghy AM, Elsaka SE. Evaluation of root canal transportation, centering ratio, and remaining dentin thickness associated with ProTaper Next instruments with and without glide path. J Endod. 2014 Dec;40(12):2053-6. https://doi.org/10.1016/i.joen.2014.09.001

2. Hartmann RC, Peters OA, Figueiredo JA, Rossi-Fedele G. Association of manual or engine-driven glide path preparation with canal centring and apical transportation: a systematic review. Int Endod J. 2018 Nov;51(11):1239-52. https://doi.org/10.1111/iej.12943

3. Berutti E, Cantatore G, Castellucci A, Chiandussi G, Pera F, Migliaretti G,et al. Use of nickel-titanium rotary PathFile to create the glide path: comparison with manual preflaring in simulated root canals. J Endod. 2009 Mar;35(3):408-412. https://doi.org/10.1016/i.joen.2008.11.021

4. D'Amario M, Baldi M, Petricca R, De Angelis F, El Abed R, D'Arcangelo C. Evaluation of a new nickel-titanium system to create the glide path in root canal preparation of curved canals. J Endod. 2013 Dec;39(12):1581-4. https://doi.org/10.1016/i.joen.2013.06.037

5. Pasqualini D, Bianchi CC, Paolino DS, Mancini L, Cemenasco A, Cantatore G, et al. Computed micro-tomographic evaluation of glide path with nickel-titanium rotary PathFile in maxillary first molars curved canals. J Endod. 2012 Mar;38(3):389-93. https://doi.org/10.1016/i.joen.2011.11.011

6. Adıgüzel M, Yılmaz K, Tüfenkçi P. Comparison of postoperative pain intensity after using reciprocating and continuous rotary glide path systems: a randomized clinical trial. Restor Dent Endod. 2019 Feb;44(1):e9. https://doi.org/10.5395/rde.2019.44.e9

7. De-Deus G, Belladonna FG, Souza EM, Alves VO, Silva EJ, Rodrigues E, et al. Scouting Ability of 4 Pathfinding Instruments in Moderately Curved Molar Canals. J Endod. 2016 Oct;42(10):1540-4. https://doi.org/10.1016/i.joen.2016.07.001

8. West JD. The endodontic Glidepath: "Secret to rotary safety". Dent Today. 2010 Sep;29(9):86-93.

9. Berutti E, Negro AR, Lendini M, Pasqualini D. Influence of manual preflaring and torque on the failure rate of ProTaper rotary instruments. J Endod. 2004 Apr;30(4):228-30. https://doi.org/10.1097/00004770-200404000-00011

10. Dagna A, El Abed R, Hussain S, Abu-Tahun IH, Visai L, Bertoglio F, et al. Comparison of apical extrusion of intracanal bacteria by various glide-path establishing systems: an in vitro study. Restor Dent Endod. 2017 Nov;42(4):316-23. https://doi.org/10.5395/rde.2017.42.4.316

11. Gunes B, Yesildal Yeter K. Effects of different glide path files on apical debris extrusion in curved root canals. J Endod. 2018 Jul;44(7):1191-4. https://doi.org/10.1016/i.joen.2018.04.012

12. Ahn SY, Kim HC, Kim E. Kinematic effects of nickel-titanium instruments with reciprocating or continuous rotation motion: a systematic review of in vitro studies. J Endod. 2016 Jul;42(7):1009-17. https://doi.org/10.1016/i.joen.2016.04.002

13. Kim HC, Kwak SW, Cheung GS, Ko DH, Chung SM, Lee W. Cyclic fatigue and torsional resistance of two new nickel-titanium instruments used in reciprocation motion: reciproc versus WaveOne. J Endod. 2012 Apr;38(4):541-4. https://doi.org/10.1016/i.joen.2011.11.014

14. Karataş E, Arslan H, Kırıcı DÖ, Alsancak M, Çapar ID. Quantitative evaluation of apically extruded debris with Twisted File Adaptive instruments in straight root canals: reciprocation with different angles, adaptive motion and continuous rotation. Int Endod J. 2016 Apr;49(4):382-5. https://doi.org/10.1111/iej.12461

15. Caballero-Flores $H$, Nabeshima CK, Binotto E, Machado ME. Fracture incidence of instruments from a single-file reciprocating system by students in an endodontic graduate programme: a cross-sectional retrospective study. Int Endod J. 2019 Jan;52(1):13-8. https://doi.org/10.1111/iej.12982

16. Alcalde MP, Duarte MA, Bramante CM, Tanomaru-Filho M, Vasconcelos BC, Só MV, et al. Torsional fatigue resistance of pathfinding instruments manufactured from several nickel-titanium alloys. Int Endod J. 2018 Jun;51(6):697-704. https://doi.org/10.1111/iej.12879

17. Keskin C, Sivas Yilmaz Ö, Inan U, Özdemir Ö. Postoperative pain after glide path preparation using manual, reciprocating and continuous rotary instruments: a randomized clinical trial. Int Endod J. 2019 May;52(5):579-87. https://doi.org/10.1111/iej.13053

18. Vertucci FJ. Root canal morphology and its relationship to endodontic procedures. Endod Topics. 2005 Aug;10(1):3-29. https://doi.org/10.1111/j.1601-1546.2005.00129.x

19. Pruett JP, Clement DJ, Carnes DL Jr. Cyclic fatigue testing of nickel-titanium endodontic instruments. J Endod. 1997 Feb;23(2):77-85. https://doi.org/10.1016/S0099-2399(97)80250-6

20. Sattapan B, Nervo GJ, Palamara JE, Messer HH. Defects in rotary nickel-titanium files after clinical use. J Endod. 2000 Mar;26(3):161-5. https://doi.org/10.1097/00004770-200003000-00008

21. Bahia MG, Melo MC, Buono VT. Influence of simulated clinical use on the torsional behavior of nickel-titanium rotary endodontic instruments. Oral Surg Oral Med Oral Pathol Oral Radiol Endod. 2006 May;101(5):675-80. https://doi.org/10.1016/i.tripleo.2005.04.019

22. Alcalde MP, Tanomaru-Filho M, Bramante CM, Duarte MA, Guerreiro-Tanomaru JM, Camilo-Pinto J, et al. Cyclic and torsional fatigue resistance of reciprocating single files manufactured by different nickel-titanium alloys. J Endod. 2017 Jul;43(7):1186-91. https://doi.org/10.1016/i.joen.2017.03.008 
Evaluation of type of kinematics on glide path procedures and torsional fatigue resistance after preparation of moderately curved canals

23. Capar ID, Kaval ME, Ertas H, Sen BH. Comparison of the cyclic fatigue resistance of 5 different rotary pathfinding instruments made of conventional nickel-titanium wire, M-wire, and controlled memory wire. J Endod. 2015 Apr;41(4):535-8. https://doi.org/10.1016/i.joen.2014.11.008

24. Gavini G, Caldeira CL, Akisue E, Candeiro GT, Kawakami DA. Resistance to flexural fatigue of Reciproc R25 files under continuous rotation and reciprocating movement. J Endod. 2012 May;38(5):684-7. https://doi.org/10.1016/i.joen.2011.12.033

25. Adiguzel M, Tufenkci P. Comparison of the ability of Reciproc and Reciproc Blue instruments to reach the full working length with or without glide path preparation. Restor Dent Endod. 2018 Nov;43(4):e41. https://doi.org/10.5395/rde.2018.43.e41

26. De-Deus G, Cardoso ML, Belladonna FG, Cavalcante DM, Simões-Carvalho M, Souza EM, et al. Performance of Reciproc Blue R25 instruments in shaping the canal space without Glide Path. J Endod. 2019 Feb;45(2):194-8. https://doi.org/10.1016/i.joen.2018.10.011

27. Gambarini G, Piasecki L, Di Nardo D, Miccoli G, Di Giorgio G, Carneiro E, et al. Incidence of deformation and fracture of Twisted File Adaptive instruments after repeated clinical use. J Oral Maxillofac Res. 2016 Dec;7(4):e5. https://doi.org/10.5037/jomr.2016.7405

28. Pirani C, Ruggeri O, Cirulli PP, Pelliccioni GA, Gandolfi MG, Prati C. Metallurgical analysis and fatigue resistance of WaveOne and ProTaper nickel-titanium instruments. Odontology. 2014 Jul;102(2):211-6. https://doi.org/10.1007/s10266-013-0113-6

29. Lopes HP, Elias CN, Vieira MV, Siqueira JF Jr, Mangelli M, Lopes WS, et al. Fatigue Life of Reciproc and Mtwo instruments subjected to static and dynamic tests. J Endod. 2013 May;39(5):693-6. https://doi.org/10.1016/i.joen.2012.11.048

30. Vieira EP, Nakagawa RK, Buono VT, Bahia MG. Torsional behaviour of rotary NiTi ProTaper Universal instruments after multiple clinical use. Int Endod J. 2009 Oct;42(10):947-53. https://doi.org/10.1111/j.1365-2591.2009.01602.x 